\title{
Design, development, static and flight tests of reverse flow multiple nozzle solid rocket motor with high burn rate propellant
}

\author{
K. Sreejith*, Shailesh Prasad, R. Bagavathiappan, C. Prasanth, R. Jeenu, \\ J. Paul Murugan, Thomas Kurian, N. Mansu, R. Harikrishnan, G. Levin and \\ V. Eswaran \\ Solid Propulsion and Research Entity, Vikram Sarabhai Space Centre, Thiruvananthapuram 695 022, India
}

\begin{abstract}
The Vikram Sarabhai Space Centre, Thiruvananthapuram has developed a special purpose motor for Human Spaceflight Programme with four reverse flow nozzles, having cant angle of $149^{\circ}$, termed as Lowaltitude Escape Motor (LEM). This is a high-thrust short-duration motor having specific envelope constraints. New high burn rate propellant has been developed to achieve the specific mission requirements. In the design, emphasis has been given to smooth turning of internal flow, avoiding sharp edges and corners, to the specified cant angle. It has to satisfy the thermal as well as structural design requirements for the multiple nozzle openings provided, containing itself to minimum external projections and envelope. Since four ellipsoidal-shaped cut-outs from the chamber cause high stress concentrations, welding or some other joining methods are not preferable. The nozzle hardware has to be machined out of 15CDV6 steel forging with high precision. The motor is tested in the vertical mode in order to avoid exhaust gas hitting on the ground and getting deflected back to the motor. This calls for extensive thermal protection requirements for both test stand and motor subsystems. A solid rocket motor with four reverse flow nozzles has been designed, realized and twice static tested successfully. The intricacies involved in the development of LEM are presented in this article.
\end{abstract}

Keywords: Launch escape system, manned mission, multiple nozzles, reverse flow, solid rocket motors.

\section{Introduction}

THE Indian Space Research Organisation (ISRO) started solid rocket motor activities nearly four decades ago and the technology has reached its near optimum level at par with international standards. Development of specialpurpose motors also started at the Vikram Sarabhai Space Centre (VSSC), Thiruvananthapuram along with conventional stage motors, starting with the development of small and reliable solid motors for rocket-aided take-off

*For correspondence. (e-mail: sreejith_k@vssc.gov.in) of aircraft. Special-purpose motor development started in a big way along with the development of Polar and Geo-synchronous Satellite Launch Vehicles (PSLV and GSLV). Small solid motors were developed for retarding the spent stages, providing positive acceleration to the liquid upper stage before ignition, jettisoning of strap-on, stage separation, etc. In this process, VSSC has developed special-purpose motor with various cant angles up to $90^{\circ}$.

A nozzle with cant angle more than $90^{\circ}$ is termed as reverse flow nozzle, where the gases generated in the chamber are gradually turned to almost opposite direction before leaving the nozzle. The thrust direction can be suitably oriented by a number of nozzles distributed around the motor axis. The complexity of design and realization of solid motors with canted nozzle increase with higher cant angles in view of the flow turning from motor axis to nozzle axis. This can be used in systems where exhaust gas impact creates a problem or payload has to be carried on the nozzle side or specific envelope constraints are imposed. This type of motor is operational in space vehicles like Orion, Soyuz or Shenzhou ${ }^{1}$. But the development of a reverse flow multiple nozzle motor is completely new to the Indian scenario.

VSSC has developed a special-purpose motor for its Human Spaceflight Programme (HSP) with four reverse flow nozzles, having cant angle of $149^{\circ}$, known as Lowaltitude Escape Motor (LEM). The main issues to be addressed other than design of this complicated propulsion system were intricacies involved in the fabrication of reverse flow nozzle, development of new high burn rate propellant and testing/qualification of the motor in line with stringent flight specification and reliability requirements $^{2}$. The testing of the rocket in a vertical test stand with thermal protection for the motor case, test fixture, instrumentation and measurement equipments was also challenging.

\section{Necessity of reverse flow multiple nozzle motor}

In satellite launch vehicles, stage rocket system is employed with solid, liquid, gaseous or hybrid propellants. 
Stage rockets are used to provide the required thrust for specified period of time and then will get separated from the ongoing vehicle. Solid rocket motors are used as booster motors, upper-stage motors, strap-on motors and special-purpose motors in conventional launch vehicles. A reverse flow multiple nozzle motor (RFMNM) can be used for specific and unique requirements (Figure 1). This can be used when exhaust gas needs to be directed away to avoid combustion gas and particle impingement on particular vehicle parts. Even when the motor is working, attachments can be maintained on both ends of the motor and payload can be carried on the nozzle end (fore end), unlike at the aft end in conventional rocket motors. This kind of motor is highly beneficial when specific envelop constraints are to be met.

For example, in a Launch Escape System (LES) used for manned missions, solid rocket motors capable of moving the Crew Module (CM) away from and out of the path of the remaining portions of the launch vehicle are needed if an abort is called for due to launch vehicle malfunction $^{1}$. This functional requirement cannot be met by attaching a conventional solid rocket motor below CM. A special-purpose solid rocket motor attached above $\mathrm{CM}$ is a must. Either the requirement shall be fulfiled by using a Canted Scarf Multiple Nozzle Motor (CSMNM) with a tower structure, or a RFMNM. Figure 2 shows the two options of LES using RFMNM and CSMNM.

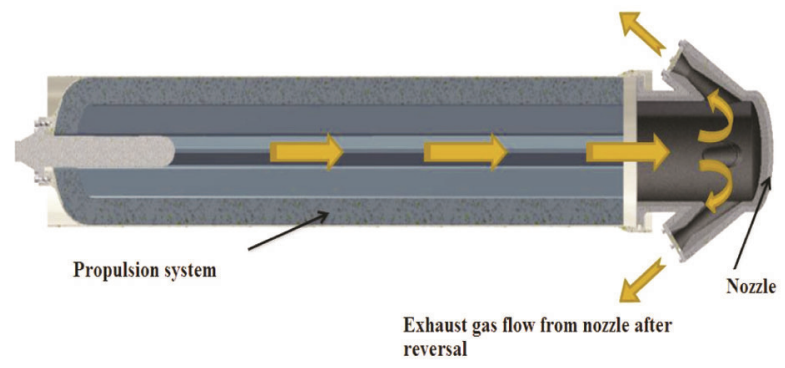

Figure 1. Gas flow path in a typical reverse flow multiple-nozzle motor (RFMNM).

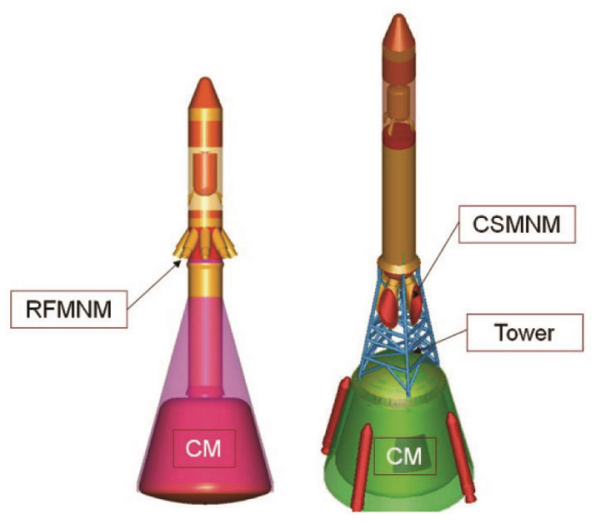

Figure 2. An artistic representation of Launch Escape System with RFMNM and Canted Scarf Multiple Nozzle Motor.
Using the RFMNM, exit gas impingement problem can be minimized whereas in case of CSMNM a heavy and tall tower will be required to avoid direct plume hitting on CM. The mass of the total system with CSMNM will be higher compared to a system based on RFMNM. The launch vehicle height can also be minimized with the use of RFMNM. Considering all the above, RFMNM is chosen for the specific requirement. Table 1 provides a comparison of conventional canted solid rocket, RFMNM and CSMNM.

\section{Crew escape system}

HSP adopts a Crew Escape System (CES) dedicated to ensure crew safety in case of exigencies at the launch pad or during the initial ascent phase of flight (during operation of the booster solid motor of the launch vehicle). CES should be capable of detaching and propelling CM away from the launch vehicle within the shortest time to a safe zone in case of any emergency/malfunctioning of the vehicle. CES includes a set of special-purpose solid motors, canards, decelerations systems, etc. to take up intended, critical and essential functioning of the Escape System. These quick-acting solid motors of CES will operate in a pre-defined sequence to provide the required thrust in line with the abort mission requirements. There are four special-purpose solid motors employed in CES of HSP: LEM (Figure 3), HEM, Pitch Motor (PM) and CES Jettisoning Motor (CJM).

The crew escape system consists of two sets of Escape Motors (solid motors), which are sized and fired such that $\mathrm{CM}$ is pulled away from the launch pad if there is explosion or occurrence of any undesired event at the launch pad. Similarly, if the flight is deviated far away from the nominal trajectory or any contingency occurs during liftoff, the Escape Motor pulls CM from the launch vehicle. The Escape Motors are configured as LEM and HEM ${ }^{2}$.

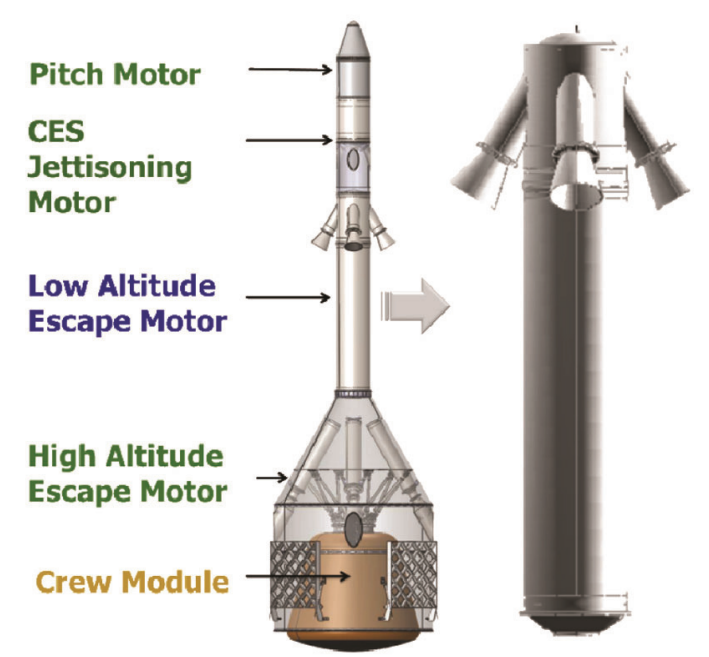

Figure 3. Crew Escape System with LEM. 
Table 1. Comparison of special purpose solid rocket motors

\begin{tabular}{|c|c|c|c|}
\hline Parameters & $\begin{array}{l}\text { Conventional canted } \\
\text { motor }\end{array}$ & $\begin{array}{l}\text { Canted scarf multiple-nozzle } \\
\text { motor (CSMNM) }\end{array}$ & $\begin{array}{l}\text { Reverse-flow multiple-nozzle } \\
\text { motor (RFMNM) }\end{array}$ \\
\hline \multicolumn{4}{|l|}{ Configuration } \\
\hline Flow & Direct flow in single nozzle & Canted flow in multiple nozzles & Reverse flow in multiple nozzles \\
\hline Thrust orientation & Along cant plane & $\begin{array}{l}\text { Resultant along axis towards } \\
\text { fore end with identical } \\
\text { nozzles } \\
\text { Side thrust possible with differen }\end{array}$ & $\begin{array}{l}\text { Resultant along axis towards aft } \\
\text { end with identical nozzles } \\
\text { hroat area. }\end{array}$ \\
\hline Payload attachment & Only at fore end & $\begin{array}{l}\text { Can be on both ends within the } \\
\text { specified envelope }\end{array}$ & Can be at both ends \\
\hline Losses & Due to canting & Due to canting and scarfing & Due to flow reversal and canting. \\
\hline Complexity in design and realization & Simple & $\begin{array}{l}\text { Complex. } \\
\text { Non-axisymetric design and } \\
\text { analysis is required. } \\
\text { Hardware fabrication and } \\
\text { linear machining and bonding } \\
\text { is difficult. }\end{array}$ & $\begin{array}{l}\text { More complex. } \\
\text { 3D flow field and impingement } \\
\text { analysis is complex. Hardware fabri- } \\
\text { cation is highly involved. Linear } \\
\text { machining, bonding and NDT are } \\
\text { much more complicated. }\end{array}$ \\
\hline
\end{tabular}

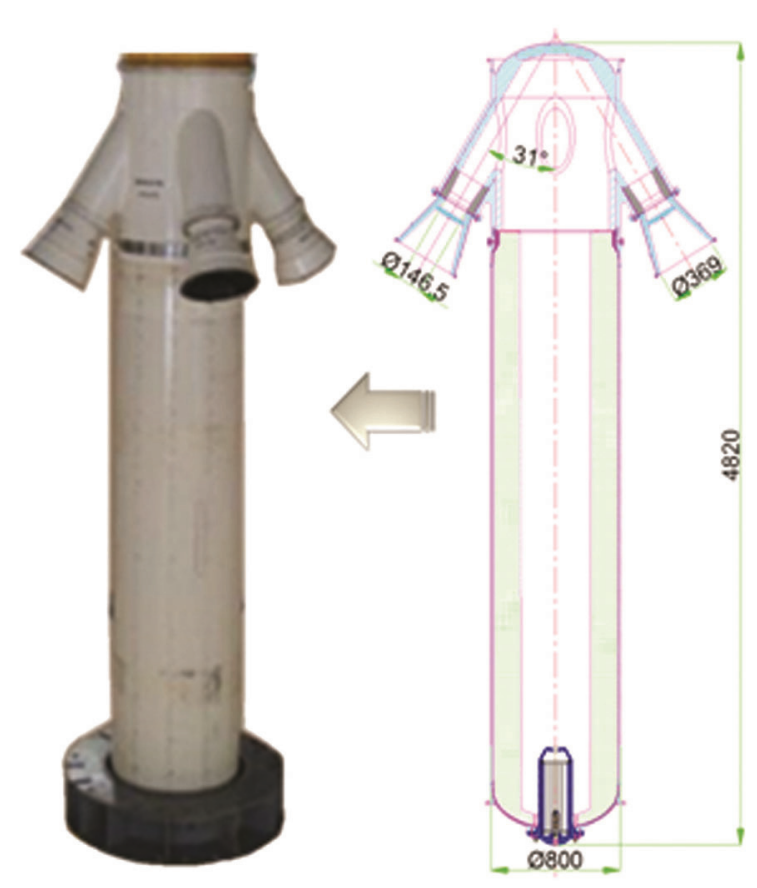

Figure 4. LEM configuration.

LEM is a distinctive special-purpose solid rocket motor with reverse flow multiple nozzles (Figure 4). In order to avoid exhaust plume impingement on CM, nozzles of LEM are required to be at the fore end of the motor case, unlike at the aft end in conventional rocket motors. This necessitates the use of a reverse flow multiple nozzle solid rocket motor.

\section{Need and development of high burn rate propellant}

LEM is a high-thrust short-duration motor with optimized envelope constraints. The motor is designed within the envelope requirement of $0.8 \mathrm{~m}$ diameter and $5 \mathrm{~m}$ length. It has to generate a thrust of $787 \mathrm{kN}$ (min) and burn for $4.6 \mathrm{sec}$. This calls for burning of $1750 \mathrm{~kg}$ of propellant within the action time of $7.1 \mathrm{sec}$, generating mass flow rate as high as $380 \mathrm{~kg} / \mathrm{s}$. The use of available standard propellants will necessitate very high operating pressure and large burn surface area for the specified mass flow rate. The system has limitations with regard to operating pressure and burn surface area also cannot be drastically increased, which will in turn violate the envelope constraints. Moreover, being a short duration motor, minimum web thickness requirements also need to be retained for proper interface configuration. Many of the propellants with high burn rate, used for igniters, were ruled out due to low rates of specific impulse. Hence development of a high burn rate propellant was mandatory without compromising much on specific impulse.

The high burn rate propellant HSPRP-1415 with ACR and Ferric oxide as burn rate accelerators, has been developed to achieve specific mission requirements. Propellant composition was an upgradation of existing hydroxyl terminated poly butadiene (HTPB)-based formulation with judicious selection of ammonium perchlorite (AP) course : fine ratio. As part of the development, many batches of the propellant formulation were processed and tested. From each propellant batch, Agni grains/RS2 motors were processed for burn rate evaluation along with cartons for mechanical property testing, EB grains for ageing studies, etc. The propellant mixing was done from laboratory level to 180,260 and $700 \mathrm{~kg}$ during development stages, and $2100 \mathrm{~kg}$ of propellant processing was carried out for casting of LEM.

Qualification of the propellant was completed with different levels of processing and casting trials. Each case study revealed that the propellant satisfactorily meets the specifications of physical, mechanical and interface properties along with ballistic parameters. 


\section{LEM design}

A detailed design and analysis process was carried out which involved grain design, thermal design, hardware design, flow field analysis, etc. ${ }^{3}$. The motor consists of 15CDV6 motor case, Rocasin insulation, case-bonded 11-lobe star grain of HTPB propellant formulation, pyrotechnic igniter and $149^{\circ}$ canted four-nozzle configuration with 15CDV6 steel back-up. The nozzle dome and divergent liners of carbon phenolic (CP) and graphite throat with silica phenolic (SP) back-up were used in the four nozzles.

In the configuration, emphasis was on smooth turning of internal flow to the specified cant angle. It has to satisfy the thermal as well as structural design requirements for multiple nozzle openings provided, containing itself to minimum external projections and envelope. Since four ellipsoidal shaped cut-outs from the chamber cause high stress concentration, welding or some other joining method is not preferable. The nozzle hardware has to be machined out of 15CDV6 steel forging with high precision (Figure 5).

The 11-lobe star grain design is chosen for this motor with the high burn rate propellant HSPRP-1415. The propellant system has a minimum structural margin of 1.4 with achieved properties.

Pyrogen igniter with metallic case and ROCASIN insulation are proposed for LEM to take care of higher operating pressure ( 225 kilogram force per square centimeter $\left.\left(\mathrm{kgf} / \mathrm{cm}^{2}\right)\right)$ and to avoid unchoking of igniter nozzle during motor action. Initiation of igniter for LEM is proposed with RMSA using two initiators.

\section{LEM fabrication}

The realization of reverse flow nozzle was the main issue. The nozzle was of a typical shape that it had four ellipsoidal cut-outs from the cylindrical nozzle chamber. These were high stress concentration regions and hence welding or some other joining methods were not acceptable. The nozzle hardware was machined out from $6800 \mathrm{~kg}$

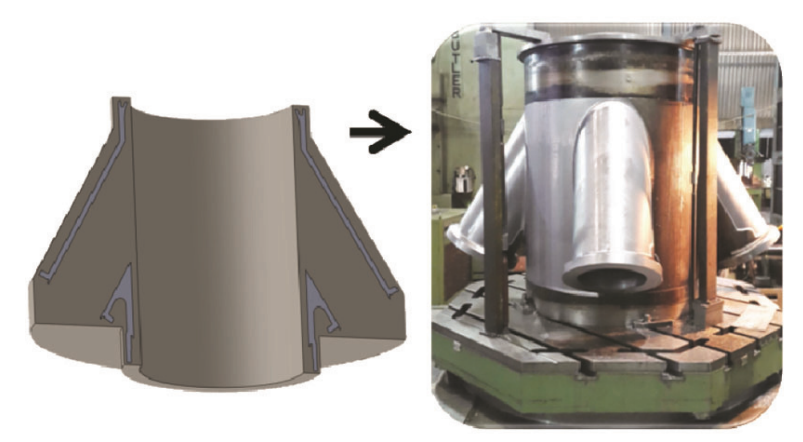

Figure 5. The $6800 \mathrm{~kg} 15 \mathrm{CDV} 6$-shaped forging machined to nozzle of $710 \mathrm{~kg}$.
15CDV6-shaped forging machined to $710 \mathrm{~kg}$ using latest fabrication methods. Realization of nozzle hardware without weld and having high dimensional precision was a real challenge. The hardware was proof pressure tested to ensure structural adequacy.

CP was used for nozzle dome liner in order to withstand hot gas impingement and flow reversal effects. Dome liner contour machining was an involved exercise. The graphite throat was backed up by a SP liner and the divergent was supported with $\mathrm{CP}$ liner.

Another challenge was the non-destructive test (NDT) requirements. Radiographic test, ultrasound test and alcohol wipe test were done on all the components and each stage of fabrication. NDT was done on all machined liners before and after bonding to hardware. Throat graphite contour machining without bonding to hardware was highly complex, intricate and cumbersome work. This enabled ultrasonic testing and visual inspection of throat in its final machined state. NDT was done in nozzle sub-assembly stage to check the integrity of the bond.

\section{LEM static test and results}

The main objectives of the static test are:

- To evaluate motor ballistic performance.

- To validate motor subsystem performance and design.

- To evaluate the thermal performance of nozzle liners, especially to confirm the erosion/ablative characteristics.

- To evaluate the igniter system performance.

- To evaluate motor side thrust due to multiple nozzles and flow reversal.

The motor was tested on a specially designed vertical test stand (Figure 6). There were nine different measurements, including thrust, pressure, strain, temperature, heat flux, acoustics, unsteady ambient pressure measurement, vibration and displacement.

Sufficient thermal protection was provided for motor case and test set-up which were exposed to exhaust gas. The test stand attachments, all the measurement devices and instrumentation wires were protected by providing proper insulation.

During the static test of solid rocket motors, at the end of motor burn out, residual heat flux in the motor was sufficient to trigger the burn out of insulation. Since the objective of static test is to verify the adequacy of the insulation provided in the motor, there is a need to quench the fire and cool the hardware immediately after motor burnout. HFC227ea (heptafluoropropane) commercially known as FM200, was used as the quenching medium. 
There were two static tests carried out as part of qualification of LEM. The motor performance was normal and close to the prediction. Post-test observations indicated normal and satisfactory performance of all the subsystems and interfaces.

Figures 7 and 8 show pressure-time and thrust-time curves for the motor respectively. The predicted lower and upper bonds are also shown in the figures.

Temperature measurements from all the 62 locations were within the predicted level. The temperature rise was observed only after the action time of the motor. Nozzle dome temperatures were almost ambient as at the convergent side, where sufficient thermal protection was provided to withstand flow impingement and reversal.

\section{Pad abort test flight}

The post-test analysis shows close match in performance of solid motors with prediction. All the strain, temperature and heat flux measurements were in good match with the prediction (Table 2).
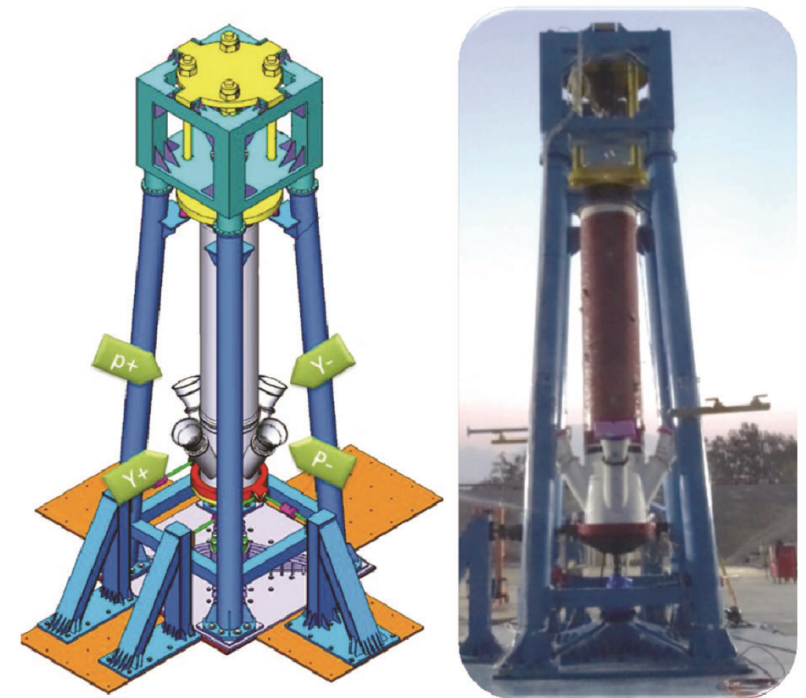

Figure 6. LEM static test stand.

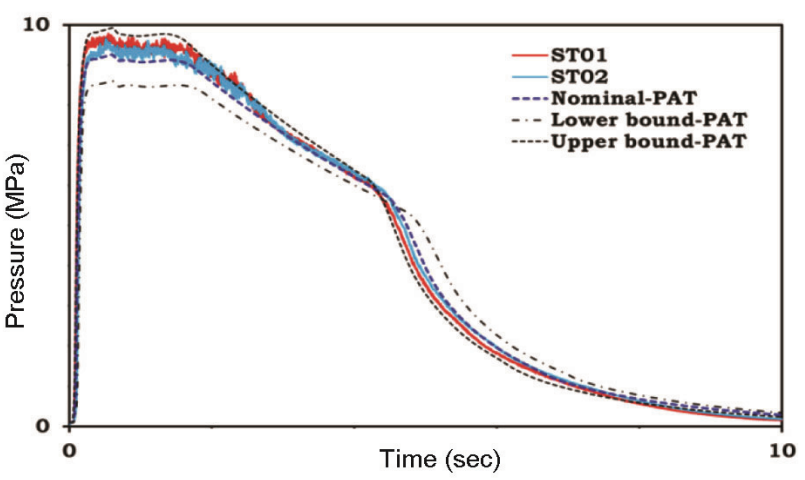

Figure 7. Pressure-time curve with prediction.
In LEM, pressure measurement was through the igniter port only, which gave igniter pressure during ignition transient period and motor pressure thereafter. Igniter chamber pressure was in good agreement with the second static test performance (Figure 9). Motor chamber pressure closely followed the nominal prediction after igniter operating period of $1.3 \mathrm{sec}$ and the simulated performance during ignition transient period showed good match with nominal prediction (Figure 10).

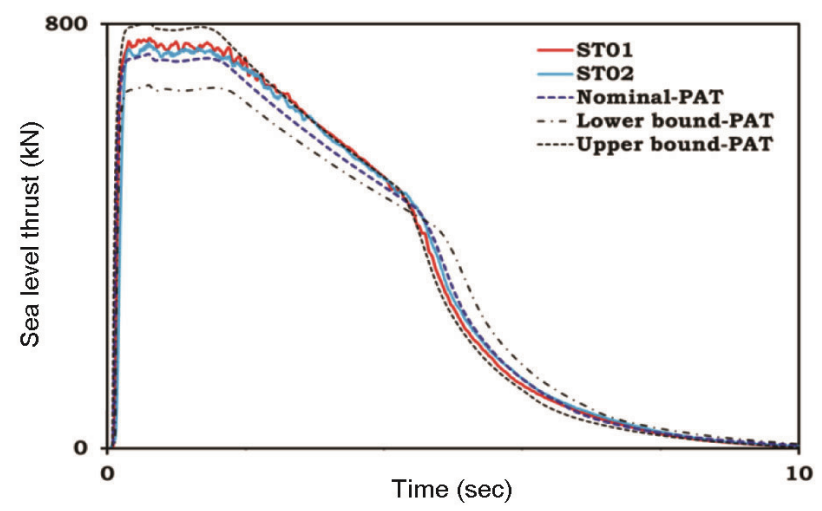

Figure 8. Thrust-time curve with prediction.

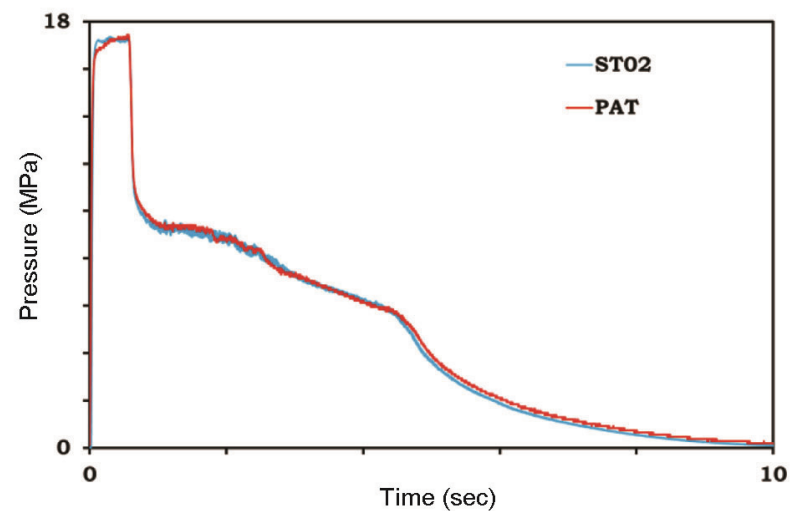

Figure 9. Igniter pressure-time curve with ST-02 performance.

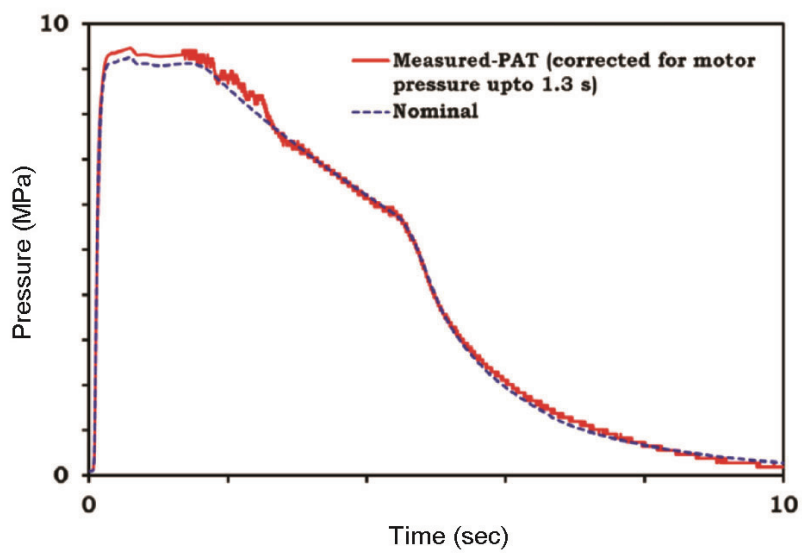

Figure 10. Motor pressure-time curve with simulated performance.

CURRENT SCIENCE, VOL. 120, NO. 1, 10 JANUARY 2021 
Table 2. Performance summary

\begin{tabular}{|c|c|c|c|c|c|}
\hline & Nominal & Lower bound & Upper bound & ST01 measured & ST02 measured \\
\hline Burn time (sec) & 4.47 & 4.71 & 4.18 & 4.32 & 4.49 \\
\hline Action time (sec) & 7.13 & 7.59 & 6.56 & 7.12 & 7.30 \\
\hline Maximum pressure (MPa) & 9.40 & 8.75 & 10.07 & 9.78 & 9.66 \\
\hline Pressure integral (MPas) & 41.2 & 40.7 & 41.4 & 41.96 & 41.96 \\
\hline Maximum sea-level thrust $(\mathrm{kN})$ & 755 & 696.6 & 815.9 & 773.6 & 764.8 \\
\hline Action time average thrust $(\mathrm{kN})$ & 455 & 418.9 & 503.3 & 466.4 & 452.7 \\
\hline Sea-level specific impulse (s) & 193 & 190 & 196 & 195 & 195.3 \\
\hline Total impulse (kNs) & 3319 & 3249.5 & 3390.6 & 3381.0 & 3359.0 \\
\hline
\end{tabular}

\section{Conclusion}

A solid rocket motor with four reverse flow nozzles has been designed, realized and twice static tested for qualification and flight tested successfully. The intricacies involved in the design and realization of RFMNM were understood and resolved. The new technology was demonstrated satisfactorily by the successful static tests and Pad Abort Test (PAT) flight. Thrust, pressure, stain and temperature, and all other measurements taken were comparable with the prediction. Post-test observations were normal and Post-test/flight analysis showed good match between predicted and measured performance. This gave satisfactory explanation for the adequacy of design methodology adopted and ensured the capability for design and development of such motors. The PAT flight performance of LEM has given enough confidence to take up the design and development of next-generation special-purpose solid motors for upcoming missions of ISRO.

1. McCarthy Jr, J. F., Ian Dodds, J. and Crowder, R. S., Development of the Apollo Launch Escape System. J. Spacecraft Aerosp. Res. Central, 1968, 5(8), 927-931.

2. Goodwin, J. L., Development of the mark $22 \bmod 4$. Naval Ordinance Station Report. AIAA-84-1417, AIAA/SAE/ASME 20th Joint Propulsion Conference, Cincinnati, Ohio, 11-13 June 1984.

3. Wong, E. Y., Solid rocket nozzle design summary. Compiled under NASA contract NAS3-10296, Sacramento, California, 23 April 1968.

doi: $10.18520 / \mathrm{cs} / \mathrm{v} 120 / \mathrm{i} 1 / 116-121$ 